Pacific Journal of Mathematics

SIMPLE PATHS ON CONVEX POLYHEDRA 


\section{SIMPLE PATHS ON CONVEX POLYHEDRA}

\section{THOMAS A BRown}

1. Introduction. In problems of linear programming, one sometimes wants to find all vertices of a given convex polyhedron. An algorithm for finding all such vertices will often define a path which passes from vertex to vertex along the edges of the polyhedron in question [1], and thus it is natural to ask, as Balinski does in [2], whether or not one can always find a path along the edges of a convex polyhedron which visits each vertex once and only once. This question has been answered in the negative independently by Grünbaum and Motzkin [5] and the author [3]. The purpose of the present paper is to present a modification of the results of [3], and answer certain questions which were asked by Grünbaum and Motzkin.

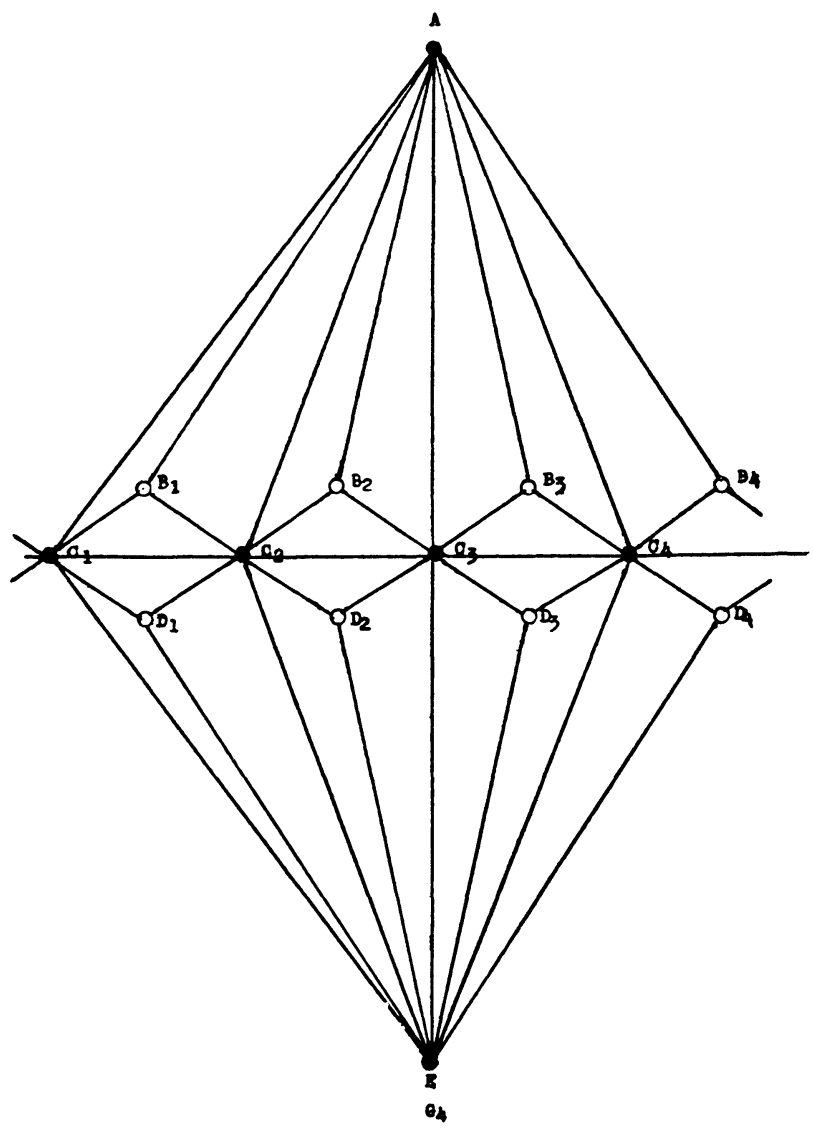

Figure 1.

Received September 5, 1960 in revised form October 20, 1960. 
2. Path numbers and path lengths. For any graph $G$ with $n(G)$ nodes we let $m(G)$ denote the number of disjoint simple paths required to cover all vertices of $G$, and let $p(G)$ denote the maximum number of nodes contained in a simple path on $G$. We call $m(G)$ the "path number" of $G$ and $p(G)$ the "path length" of $G$. If $G$ can be represented as the edges and vertices of a convex polyhedron in three-dimensional space, we say that $G$ is " 3 -polyhedral". Now let

$$
\begin{gathered}
p(n)=\min \{p(G): \quad G \text { is } 3 \text {-polyhedral and } n(G)=n\} \\
m(n)=\max \{m(G): G \text { is } 3 \text {-polyhedral and } n(G)=n\} .
\end{gathered}
$$

We will show, by means of a class of examples, that $m(n) \geqq$ $(n-10) / 3$ and $p(n) \leqq(2 n+13) / 3$ for all $n$.

3. The graphs $G_{k}$. Let the graph $G_{k}(k \geqq 3)$ have $3 k+2$ vertices, which we will denote by $a, b_{i}, c_{i}, d_{i}$, and $e(i$ ranging from 1 to $k$ ). Let the edges of $G_{k}$ be $\left(a, b_{i}\right),\left(a, c_{i}\right),\left(e, d_{i}\right),\left(e, c_{i}\right),\left(c_{i}, c_{i+1}\right),\left(c_{i}, b_{i}\right),\left(c_{i}, d_{i}\right)$, $\left(d_{i}, c_{i+1}\right)$, and $\left(b_{i}, c_{i+1}\right)$. Thus $a$ and $e$ are of valence $2 k$, the $c_{i}$ are of valence 8 , and the $b_{i}$ and $d_{i}$ are of valence 3 . See Figure 1 for a drawing of $G_{4} . \quad G_{k}$ can be represented as a triangulation of the plane, and it is easy to show by induction [4] that if $n(G) \geqq 4$ and $G$ can be

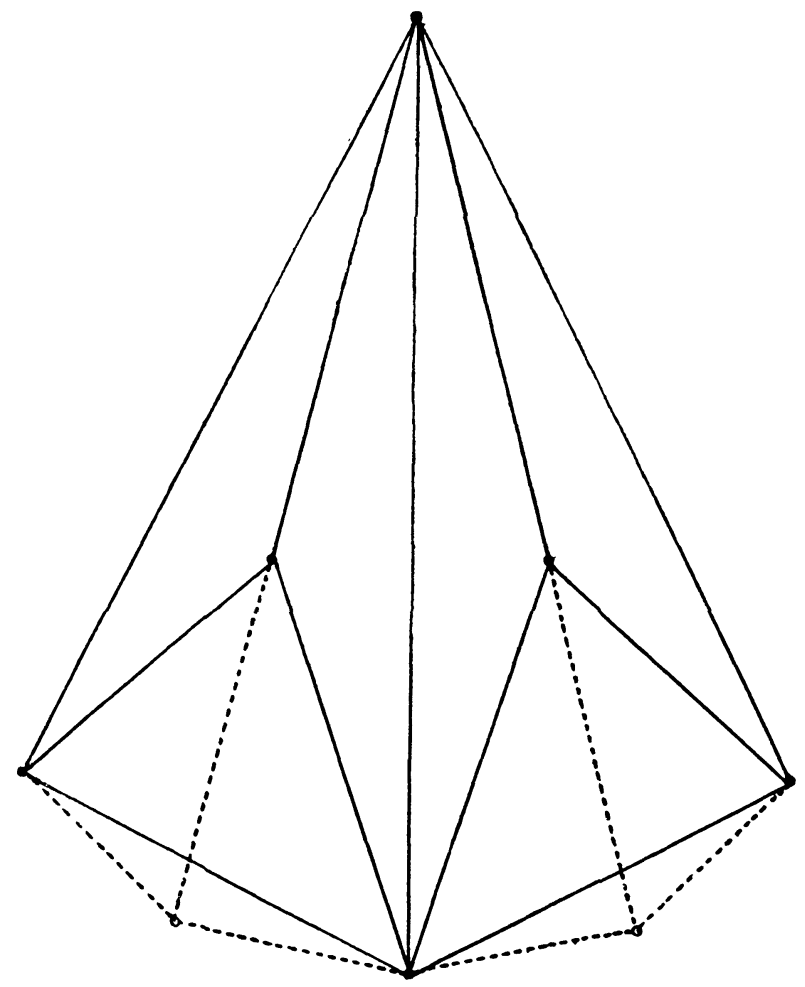

Figure 2. 
represented as a triangulation of the plane, then $G$ can be represented as the edges and vertices of a convex polyhedron in 3-space. Alternatively, one could apply the "Fundamentalsatz der Konvexen Typen" of E. Steinitz [6]. But in the case of $G_{k}$ it is really unnecessary to use any such general results, for $G_{k}$ is clearly the graph of the polyhedron obtained by appropriately truncating a bipyramid whose base is a regular $2 k$-gon (Figure 2 illustrates how the top half of a bipyramid should be truncated in obtaining $G_{4}$ ).

If we color $a, c_{i}$, and $e$ black and let $b_{i}$ and $d_{i}$ be white (where $i$ ranges from 1 to $k$ ), then $G_{k}$ consists of $n+2$ black nodes and $2 n$ white ones. Since each white node has only black neighbors, each simple path in $G_{k}$ must contain at most one more white node than black. Thus at least $2 k-(k+2)=k-2$ disjoint simple paths are required to visit every node of $G_{k}$. The following set of paths shows that the pathnumber of $G_{k}$ is, in fact, exactly $k-2$ :

$$
\begin{aligned}
& b_{1} \rightarrow c_{1} \rightarrow d_{1} \rightarrow e \rightarrow d_{2} \rightarrow c_{2} \rightarrow b_{2} \rightarrow a \rightarrow b_{3} \rightarrow c_{3} \rightarrow d_{3} \\
& b_{i} \rightarrow c_{i} \rightarrow d_{i} \quad(i=4, \cdots, k) .
\end{aligned}
$$

Similarly, since no simple path can contain more than $k+2$ black vertices, it follows that no simple path can contain more than

$$
(k+2)+(k+3)=2 k+5
$$

vertices. It is easy to construct simple paths containing exactly this many vertices, and thus the path-length of $G_{k}$ is $2 k+5$. Since $n\left(G_{k}\right)=$ $3 k+2$, it follows that if $n \equiv 2(\bmod 3)$,

$$
\begin{aligned}
& p(n) \leqq \frac{2 n+11}{3} \\
& m(n) \geqq \frac{n-8}{3} .
\end{aligned}
$$

To get bounds for $n \equiv 1(\bmod 3)$, consider the graph $G_{k}^{-}$obtained by omitting one white vertex from $G_{k}$. For $n \equiv 0(\bmod 3)$, consider the graph $G_{k}^{+}$obtained by adjoining to $G_{k}$ a vertex connected to $c_{1}, d_{1}$, and

e. It follows that

$$
\left.\left.\begin{array}{ll}
p(n) \leqq \frac{2 n+13}{3} \\
m(n) \geqq \frac{n-10}{3}
\end{array}\right\} \begin{array}{ll} 
& p(n) \leqq \frac{2 n+13}{3} \\
& m(n) \geqq \frac{n-9}{3}
\end{array}\right\} n \equiv 0(\bmod 3) .
$$

Grünbaum and Motzkin asked if $n(G)=p(G)$ provided all of the faces of the polyhedron representing $G$ were triangles, and our examples 
show that this is not the case. They further conjectured that

$$
\max _{n(\theta)=n} m(G) \cdot p(G) \geqq n^{1+\gamma} \quad \text { for some } \gamma>0 .
$$

Our examples show that

$$
\max _{n(G)=n} m(G) \cdot p(G) \geqq \frac{2 n^{2}-7 n 130}{9} .
$$

Thus for any $\gamma<1$ we can find an $N_{\gamma}$ such that

$$
\max _{n(G)=n} m(G) \cdot p(G)>n^{1+\gamma} \quad \text { for all } n \geqq N_{\gamma} \text {. }
$$

Furthermore, this result is the best possible in a sense; for since $m(G)<n$ and $p(G) \leqq n$, it follows that

$$
\max _{n(G)=n} m(G) \cdot p(G)<n^{2}
$$

for all $n$.

I want to thank Dr. Michel Balinski for drawing this subject to my attention, and the referee for making me aware of the paper by Grünbaum and Motzkin.

\section{BIBLIOGRAPHY}

1. Michel L. Balinski, An Algorithm for Finding All Vertices of Convex Polyhedral Sets, Doctoral Dissertation, Princeton University, June 1959.

2. - On the graph structure of convex polyhedra in $n$-space. Pacific J. Math., (to appear).

3. T. A. Brown, Hamiltonian Paths on Convex Polyhedra, unpublished note, the RAND Corporation, August, 1960.

4. - The Representation of Planar Graphs by Convex Polyhedra, unpublished note, the RAND Corporation, August, 1960.

5. B. Grünbaum, and T. S. Motzkin, Longest Simple Paths in Polyhedral Graphs, (to appear).

6. E. Steinitz, and H. Rademacher, Vorlesungen über die Theorie des Polyeder, Springer, Berlin. 1934.

THE RAND CORPORATION AND HARVARD UNIVERSITY 


\section{PACIFIC JOURNAL OF MATHEMATICS}

\section{EDITORS}

\author{
RaLPh S. Phillips \\ Stanford University \\ Stanford, California \\ F. H. BRowNELL \\ University of Washington \\ Seattle 5 , Washington
}

A. L. Whiteman

University of Southern California

Los Angeles 7, California

L. J. Paige

University of California

Los Angeles 24, California

\author{
E. F. BECKENBACH \\ T. M. CHERRY
}

\author{
ASSOCIATE EDITORS

$\begin{array}{lll}\text { D. DERRY } & \text { H. L. ROYDEN } & \text { E. G. STRAUS } \\ \text { M. OHTSUKA } & \text { E. SPANIER } & \text { F. WOLF }\end{array}$

\section{SUPPORTING INSTITUTIONS}

\author{
UNIVERSITY OF BRITISH COLUMBIA \\ CALIFORNIA INSTITUTE OF TECHNOLOGY \\ UNIVERSITY OF CALIFORNIA \\ MONTANA STATE UNIVERSITY \\ UNIVERSITY OF NEVADA \\ NEW MEXICO STATE UNIVERSITY \\ OREGON STATE COLLEGE \\ UNIVERSITY OF OREGON \\ OSAKA UNIVERSITY \\ UNIVERSITY OF SOUTHERN CALIFORNIA
}

\author{
STANFORD UNIVERSITY \\ UNIVERSITY OF TOKYO \\ UNIVERSITY OF UTAH \\ WASHINGTON STATE COLLEGE \\ UNIVERSITY OF WASHINGTON \\ AMERICAN MATHEMATICAL SOCIETY \\ CALIFORNIA RESEARCH CORPORATION \\ HUGHES AIRCRAFT COMPANY \\ SPACE TECHNOLOGY LABORATORIES \\ NAVAL ORDNANCE TEST STATION
}

Mathematical papers intended for publication in the Pacific Journal of Mathematics should be typewritten (double spaced), and the author should keep a complete copy. Manuscripts may be sent to any one of the four editors. All other communications to the editors should be addressed to the managing editor, L. J. Paige at the University of California, Los Angeles 24, California.

50 reprints per author of each article are furnished free of charge; additional copies may be obtained at cost in multiples of 50 .

The Pacific Journal of Mathematics is published quarterly, in March, June, September, and December. The price per volume (4 numbers) is $\$ 12.00$; single issues, $\$ 3.50$. Back numbers are available. Special price to individual faculty members of supporting institutions and to individual members of the American Mathematical Society: $\$ 4.00$ per volume; single issues, $\$ 1.25$.

Subscriptions, orders for back numbers, and changes of address should be sent to Pacific Journal of Mathematics, 103 Highland Boulevard, Berkeley 8, California.

Printed at Kokusai Bunken Insatsusha (International Academic Printing Co., Ltd.), No. 6, 2-chome, Fujimi-cho, Chiyoda-ku, Tokyo, Japan.

\section{PUBLISHED BY PACIFIC JOURNAL OF MATHEMATICS, A NON-PROFIT CORPORATION}

The Supporting Institutions listed above contribute to the cost of publication of this Journal, but they are not owners or publishers and have no responsibility for its content or policies.

Reprinted 1966 in the United States of America 


\section{Pacific Journal of Mathematics}

\section{Vol. 11, No. 4}

A. V. Balakrishnan, Prediction theory for Markoff processes . . . . . . . . . . 1171

Dallas O. Banks, Upper bounds for the eigenvalues of some vibrating systems . . . . 1183

A. Białynicki-Birula, On the field of rational functions of algebraic groups ...... 1205

Thomas Andrew Brown, Simple paths on convex polyhedra .............. 1211

L. Carlitz, Some congruences for the Bell polynomials . . . . . . . . . . . . 1215

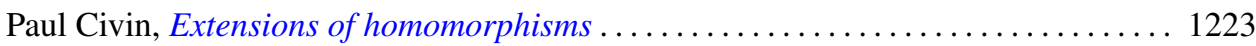

Paul Joseph Cohen and Milton Lees, Asymptotic decay of solutions of differential

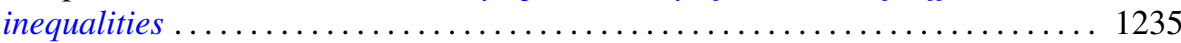

István Fáry, Self-intersection of a sphere on a complex quadric . . . . . . . . . . 1251

Walter Feit and John Griggs Thompson, Groups which have a faithful representation

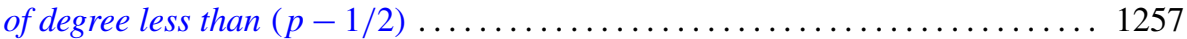

William James Firey, Mean cross-section measures of harmonic means of convex

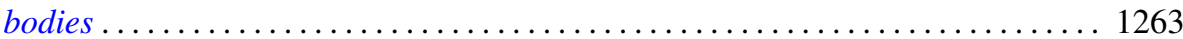

Avner Friedman, The wave equation for differential forms . . . . . . . . . . 1267

Bernard Russel Gelbaum and Jesus Gil De Lamadrid, Bases of tensor products of

Banach spaces ................................... 1281

Ronald Kay Getoor, Infinitely divisible probabilities on the hyperbolic plane . . . . 1287

Basil Gordon, Sequences in groups with distinct partial products . . . . . . . . . . . . 1309

Magnus R. Hestenes, Relative self-adjoint operators in Hilbert space . . . . . . . . . 1315

Fu Cheng Hsiang, On a theorem of Fejér ......................... 1359

John McCormick Irwin and Elbert A. Walker, On N-high subgroups of Abelian

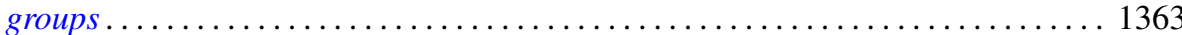

John McCormick Irwin, High subgroups of Abelian torsion groups . . . . . . . . . 1375

R. E. Johnson, Quotient rings of rings with zero singular ideal . . . . . . . . . . . 1385

David G. Kendall and John Leonard Mott, The asymptotic distribution of the time-to-escape for comets strongly bound to the solar system ...

Kurt Kreith, The spectrum of singular self-adjoint elliptic operators ....

Lionello Lombardi, The semicontinuity of the most general integral of the calculus of variations in non-parametric form ................................

Albert W. Marshall and Ingram Olkin, Game theoretic proof that Chebyshev inequalities are sharp

Wallace Smith Martindale, III, Primitive algebras with involution . . William H. Mills, Decomposition of holomorphs ..............

James Donald Monk, On the representation theory for cylindric algebras . . . . . . 1447

Shu-Teh Chen Moy, A note on generalizations of Shannon-McMillan theorem . . . . 1459

Donald Earl Myers, An imbedding space for Schwartz distributions . .

John R. Myhill, Category methods in recursion theory .........

Paul Adrian Nickel, On extremal properties for annular radial and circular slit mappings of bordered Riemann surfaces

Edward Scott O'Keefe, Primal clusters of two-element algebras . .

Nelson Onuchic, Applications of the topological method of Wazewski to certain

problems of asymptotic behavior in ordinary differential equations ...

Peter Perkins, A theorem on regular matrices................

Clinton M. Petty, Centroid surfaces .... 